\title{
Complex Urban Systems: Challenges and Integrated Solutions for the Sustainability and Resilience of Cities
}

\author{
Riccardo Gallotti $\mathbb{D}^{1}{ }^{1}$ Pierluigi Sacco $\mathbb{D D}^{1,2}$ and Manlio De Domenico ${ }^{1}{ }^{1}$ \\ ${ }^{1}$ Fondazione Bruno Kessler, Via Sommarive 18, 38123 Povo, TN, Italy \\ ${ }^{2}$ IULM University, Via Carlo Bo. 1, 20143 Milano, Italy \\ Correspondence should be addressed to Riccardo Gallotti; rgallotti@gmail.com, Pierluigi Sacco; pierluigi.sacco@iulm.it, and \\ Manlio De Domenico; mdedomenico@fbk.eu
}

Received 2 July 2020; Revised 9 March 2021; Accepted 4 September 2021; Published 5 October 2021

Academic Editor: Rosa M. Benito

Copyright (c) 2021 Riccardo Gallotti et al. This is an open access article distributed under the Creative Commons Attribution License, which permits unrestricted use, distribution, and reproduction in any medium, provided the original work is properly cited.

\begin{abstract}
For decades, from design theory to urban planning and management, from social sciences to urban environmental science, cities have been probed and analyzed from the partial perspective of single disciplines. The digital era, with its unprecedented data availability, is allowing for testing old theories and developing new ones, ultimately challenging relatively partial models. Our community has been in the last years providing more and more compelling evidence that cities are complex systems with emergent phenomena characterized by the collective behavior of their citizens who are themselves complex systems. However, more recently, it has also been shown that such multiscale complexity alone is not enough to describe some salient features of urban systems. Multilayer network modeling, accounting for both multiplexity of relationships and interdependencies among the city's subsystems, is indeed providing a novel integrated framework to study urban backbones, their resilience to unexpected perturbations due to internal or external factors, and their human flows. In this paper, we first offer an overview of the transdisciplinary efforts made to cope with the three dimensions of complexity of the city: the complexity of the urban environment, the complexity of human cognition about the city, and the complexity of city planning. In particular, we discuss how the most recent findings, for example, relating the health and wellbeing of communities to urban structure and function, from traffic congestion to distinct types of pollution, can be better understood considering a city as a multiscale and multilayer complex system. The new challenges posed by the postpandemic scenario give to this perspective an unprecedented relevance, with the necessity to address issues of reconstruction of the social fabric, recovery from prolonged psychological, social and economic stress with the ensuing mental health and wellbeing issues, and repurposing of urban organization as a consequence of new emerging practices such as massive remote working. By rethinking cities as large-scale active matter systems far from equilibrium which consume energy, process information, and adapt to the environment, we argue that enhancing social engagement, for example, involving citizens in codesigning the city and its changes in this critical postpandemic phase, can trigger widespread adoption of good practices leading to emergent effects with collective benefits which can be directly measured.
\end{abstract}

\section{Introduction}

Cities offer one of the most challenging test beds for any complexity-oriented modeling approach. The reason is simple: they present a multiscale structure integrating a multitude of social and technological subsystems. While being large enough to be amenable to macromodeling, at the same time, they are not large enough to be exclusively approached at that scale, thus raising ambition for detailed microstructural analysis and understanding. For these reasons, the modeling and analysis of cities sit naturally at the mesoscale, at the edge between micro and macro, and offer an ideal environment for the development of "statistical mechanics" of human interaction.

On the basis of these premises, it is paradoxically not surprising that the most authoritative and celebrated account of how cities "work," which has informed a countless number of different approaches and analysis of all sorts, is Jane Jacobs' book "The Death and Life of Great American Cities" [1], which is essentially an autoethnography of the 
experience of the city par excellence, New York City, that is, an approach that could not be farther away from conventional scientific standards: subjective observations about a single city through time. Despite its lack of "hard scientific" method, the book has been so influential and was celebrated to become a sort of conceptual map for all scientists aiming at building solid scientific explanations and analyses of the urban dynamics. Such influence stems from its unique capacity of summing up, through the author's gaze, so many different, subtly related aspects of the essence of cities' functioning and living. Not incidentally, one of its major insights among many is that cities thrive only if they are able to maintain their own form of highly idiosyncratic complexity. If they fall for structural oversimplification and loss of diversity, they decay and possibly eventually die. Traditional top-down planning practices have not successfully passed the urban complexity test, due to their inability to credibly address the mutability of social interactions in urban settings through their rigid schemes and their consequent tendency to micromanage environmental complexity rather than enable its generative potential [2]. Moreover, Jacobs' lesson reminds us that the complexity of the city is not only about the manifold aspects of the urban environment and their interrelations but also about the complexity of our own mental representation of the city. Jacobs' insights are also about what planning means for the city and about the subtle balance between self-organization and intelligent design, and here too there is enormous inspiration for readers who are accustomed to think in complexity science terms. There are, therefore, at least three different dimensions of complexity that one should keep in mind thinking of the city: the complexity of the urban environment, the complexity of human cognition about the city, and the complexity of city planning. A comprehensive approach to urban complexity should be able to encompass all three and even more so in the complex postpandemic scenario with which all cities will have to cope in the coming years.

\section{Modeling Urban Complexity}

Research on the complexity of urban environments has a long tradition, and although its roots are difficult to trace back, a fundamental text is Christopher Alexander's “A City Is Not a Tree" [3]. In this short, insightful essay, later developed into a book [4], Alexander makes use of biological analogies to explore the inherent geometrical properties of urban organization, largely prefiguring the complexity science of the next two decades. As shown in his later book [5], Alexander clearly understands the relationship between the emergent macrostructures of the city and the microlevel of building construction patterns and their compositional space grammar, thus characterizing architectural building rules as subject to adaptive pressures. Alexander then goes further on [6] to identify vernacular architecture as a self-organizing system of space organization which reflects an extremely complex system of socioenvironmental cognition and constitutes an ideal bridge between the complexity science of urban environments and that of their mental representations. Finally, in the monumental 4-book series, "The Nature of Order" [7-10], Alexander arrives at an all-encompassing evolutionary synthesis of human and biological organization structures, where he finally investigates issues such as why certain human settlements have more "life" in them than others. One might think of a city's "liveliness" in terms of an ensemble of emergent structural properties that result from the coevolution of built environments and human interaction, following a logic that closely resembles that of biological design.

It is from these bases that the literatures on shape grammars [11], space syntax [12], and their inevitable confluences [13] take off, building the premises of a computational approach to urban form and function. The marriage with the concurrently upcoming complexity science would not only be inevitable $[14,15]$ but necessary, with the urban dimension becoming one of the natural testing grounds for fractal [16], agent-based [17], and cellular automata modeling [18] of the emergent order properties of multiscale systems, once again naturally coalescing into a unified theory of urban complexity [19].

Complexity-based approaches to urban issues have since then proliferated to practically every sphere of city life [20, 21]: transportation systems [22], utilities and infrastructure [23, 24], pollution [25], and crime [26], just to limit ourselves to a few examples. These approaches have allowed the development of much deeper insights into the nature and effects of structural interdependencies across urban environments [27], also deriving from the unique tension between the general nonlinear effects typical of all urban environments with local, specific factors and dynamics $[28,29]$. The rapidly increasing availability of large databases and the big data revolution in social and urban sciences has further boosted this tendency, leading to a new wave of complexity-oriented urban science which is likely still in its early phase [30], and it is consequently challenged by the need of developing proper analytical methods for the extraction of reliable behavioral information [31, 32]. There is therefore room to expect that the application of complexity science to the modeling, analysis, and understanding of urban systems is a long-term scientific endeavor rather than a transitory phase and that this will have profound effects on many dimensions of science, society, and the economy.

From a complexity science perspective, cities cannot be simply viewed as structures in space but also as functional systems of flows and networks [33]. In 1961, Gilbert used a special class of networks, namely, random geometric graphs, to model the structure of spatially embedded networks and the effects of spatial constraints on the system [34]. The core idea is to consider spatially distributed nodes representing, for instance, geographic areas which are connected to each other if their distance is within some spatial scale used as a reference. This class of models is desirable for studying the structure and the function of complex systems like a city, consisting of areas connected by transportation infrastructures [35].

Nowadays, network modeling and analysis of urban ecosystems is a widely adopted framework to cope with the 
complexity of cities and of their societies at different scales [36]. The analysis of the Boston underground transportation system through the lens of global and local efficiency in information flows revealed that its underlying logic of construction is, in fact, a small-world principle [37]. Complex networks have been used for geographical modeling and, by means of combined cellular models of land and behavior, it has been shown that they provide a compelling framework for growth dynamic that is consistent with largescale regularities, such as fractality or power-law scaling relations [38]. The analysis of the dual graph representation, where roads and junctions are mapped into nodes and edges, respectively, of six urban street networks characterized by different patterns and historical roots revealed their unique connectivity patterns with respect to nongeographic systems [39]. Network science has been used for spatial analysis of the topology of Singapore inferred from human-generated data, by identifying city hubs, centers, and other elements which are essential to characterize urban interactions. Results from longitudinal analysis suggest that Singapore is rapidly developing towards the designed polycentric urban form [40]. An example of network analysis in action is shown in Figure 1.

Models and analytical tools borrowed from or inspired by complexity science are proliferating, providing convincing evidences of their application to real cities [42-46], from human mobility [47-50] and traffic congestion [51-55] to energy consumption [56], air quality [57, 58], climate [59], and health and wellbeing [60-63], as well as accessibility to important facilities like hospitals [64]. The city is seen as a huge complex system which grows and expands $[65,66]$ and whose spatial organization $[67,68]$ dynamically experiences a transition from monocentric to polycentric $[69,70]$.

The relevance of complexity modeling tools to understand urban ecosystems ignited an unprecedented deluge of open and crowdsourced information about the topology of the city and its fundamental constituents [71, 72], as well as about its function, directly related to the behavior of its inhabitants inferred from the data they generate, such as phone call detail records [47, 73-77], transactions [78-83], GPS trajectories [49, 84-88], and geo-tagged social media [89-101].

2.1. The Multilayer Structure of the City. Very recently, it has been suggested that a new level of complexity characterizes cities. In fact, accounting for multiplexity $[102,103]$ of transportation, that is, multimodality [104] (see Figure 2), and interdependencies $[105,106]$, that is, structural and functional relationships with other systems (see Figure 3), allows, on the one hand, to gain new insights about the functioning of a city and the complex society it hosts. On the other hand, it allows to better understand its resilience to targeted policies, such as infrastructural interventions, or to random perturbations, such as unexpected failures in transportation or energy networks, as well as catastrophic events.
Multilayer models for transportation infrastructures $[104,107,108]$ group together connections from the same transportation mode, assign them to a layer, and sometimes couple layers with each other, the last one depending on whether information about time or economic cost to move across layers is available or not [109].

Different perspectives can be adopted. For instance, one might assign different submodes (e.g., distinct lines of the tube) to different layers $[110,111]$ or group them together within the same layer encoding a unique means of transportation [104]. The two approaches, applied to the backbone of 9 different cities in Europe, from small towns to megacities, highlighted different vulnerabilities and provided a framework for testing improvements [112]. The analysis of topological pathways across layers revealed, for instance, that London's public transportation is designed to minimize redundancies [113]. The London underground network exhibits patterns that are not observed in other systems, like social networks. The calculation of clustering, that is, the tendency to triadic closure, revealed mechanisms to avoid redundant connections, with 3-mode triangles more frequent than 2-mode triangles which, in turn, are more frequent than single-mode triangles [114]. The analysis of the interdependence between the street network and the subways of London and New York City unraveled similar mechanisms, with the underground network acting as a decentralizing force which pushes congestion towards the end of its lines. It has been found that uneven spatial distributions of accessibility might emerge if the speed of subways is increased without a systemic view of the city [115].

While transportation networks with their multiplexity and interdependency are fundamental to enhance our understanding of the city, it is similarly of utmost importance to include other systems, for example, sociotechnical and ecological ones, which are in turn shaped by urban activities, in the integrated picture required to maintain some control on city sustainability and resilience.

2.2. The Multilayer Dynamics of the City. Tightly related to the modeling of the urban backbone is the analysis of its flows. In fact, the city is a complex system consisting of geographic areas which integrate local flows of goods and people within the overall urban ecosystem. It is not surprising that modeling and understanding both individual and collective human mobility patterns $[47,49,75,116]$ play an important role in our understanding of the city: the identification and quantification of functional patterns, for example, daily mobility motifs [117], can be used to drive the development of transportation systems and enhance urban infrastructures [118].

The abundance of available urban data is already being used to better understand one of the most important urban problems: traffic congestion. Only recently the traditional assumption that people follow the minimum cost path [121] has been challenged [122], showing that routing mechanisms accounting for the complexity of the city have 


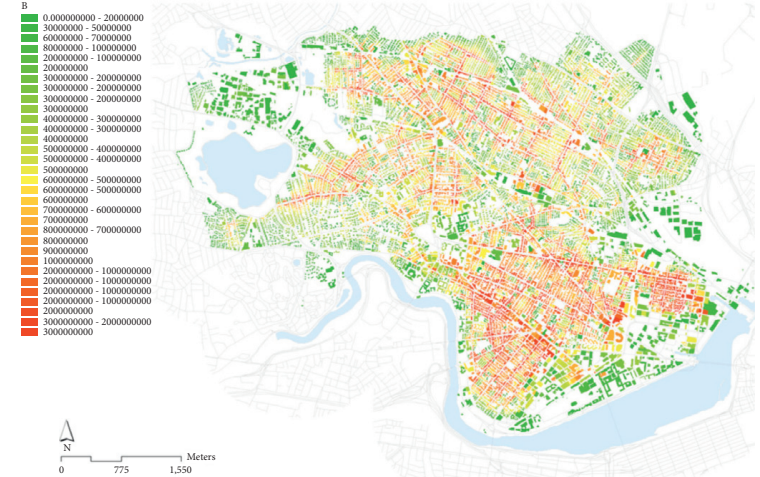

(a)

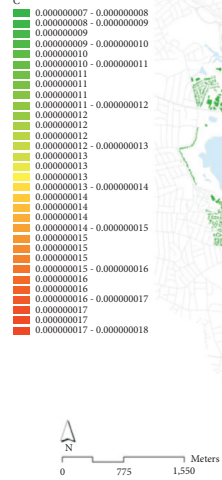

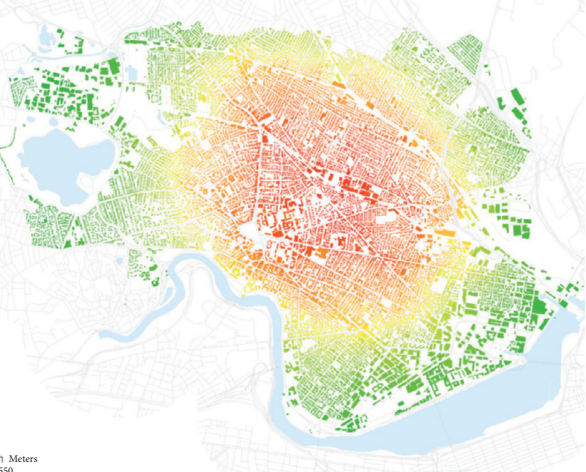

(b)

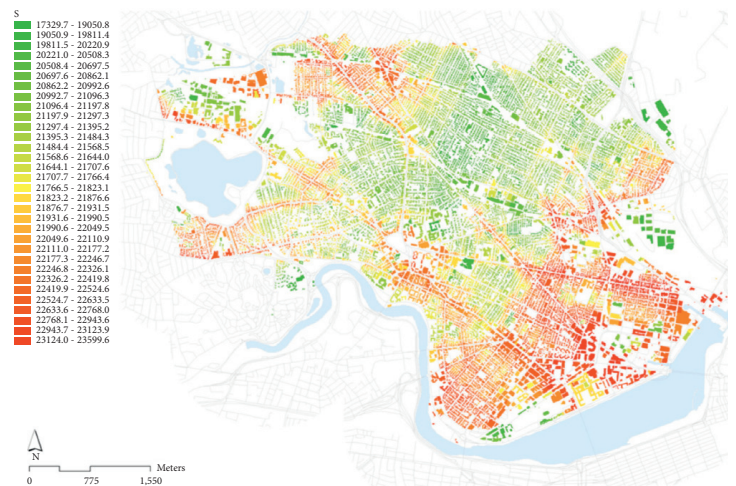

(c)

Figure 1: Analysis of an urban network. The road network of Cambridge \& Somerville (MA) as seen through the lens of network science. Nodes represent buildings and color encodes different descriptors quantifying the relevance of each node with respect to different criteria: (a) betweenness, (b) closeness, and (c) straightness centrality, respectively. Figure reproduced with permission from [41], all rights reserved.

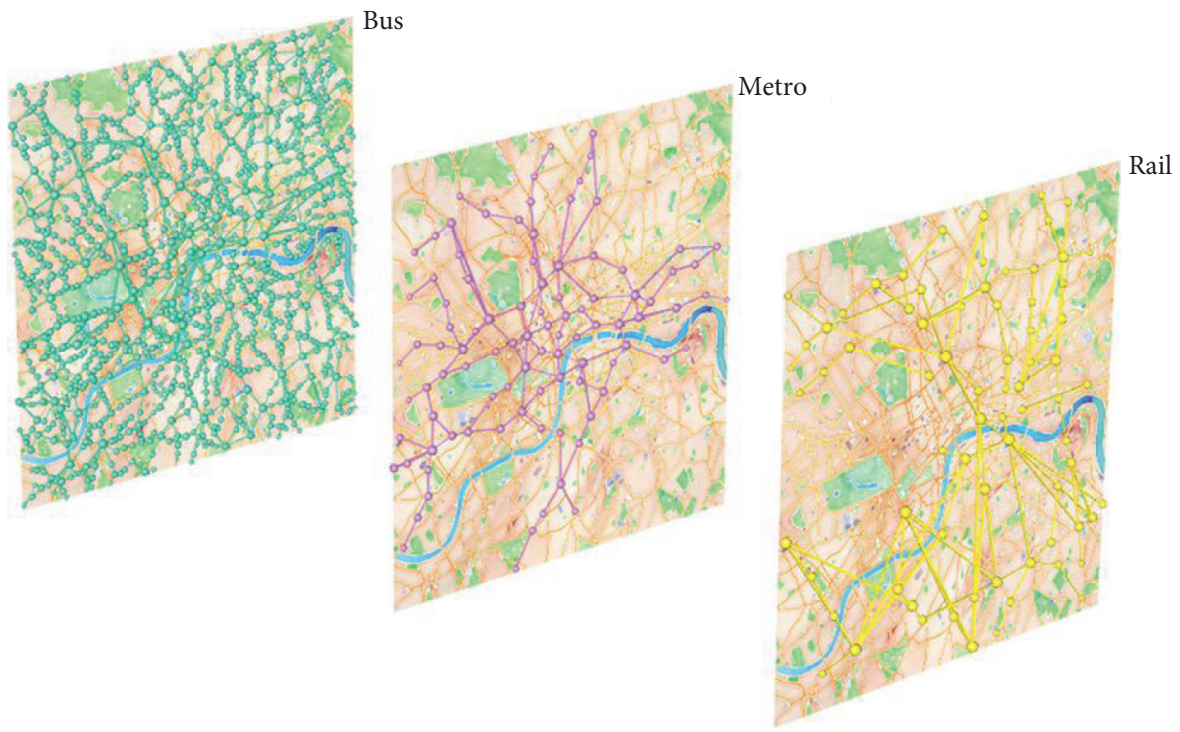

FiguRE 2: Multiplex urban transportation networks. Multimodal transportation network of London, consisting of three layers encoding different types of infrastructural connections: bus, tube, and rail. Figure reproduced with permission from [107], all rights reserved.

huge potential in mitigating traffic [53], especially in hypothetical smart cities [123]. Stochastic theories of urban growth, validated on US and OECD empirical data, show that congestion shapes cities, revealing intriguing relationships between mobility patterns and scaling laws, such as the dependence on population size of the total number of miles driven daily, the total length of the road network, the total traffic delay, the total consumption of 


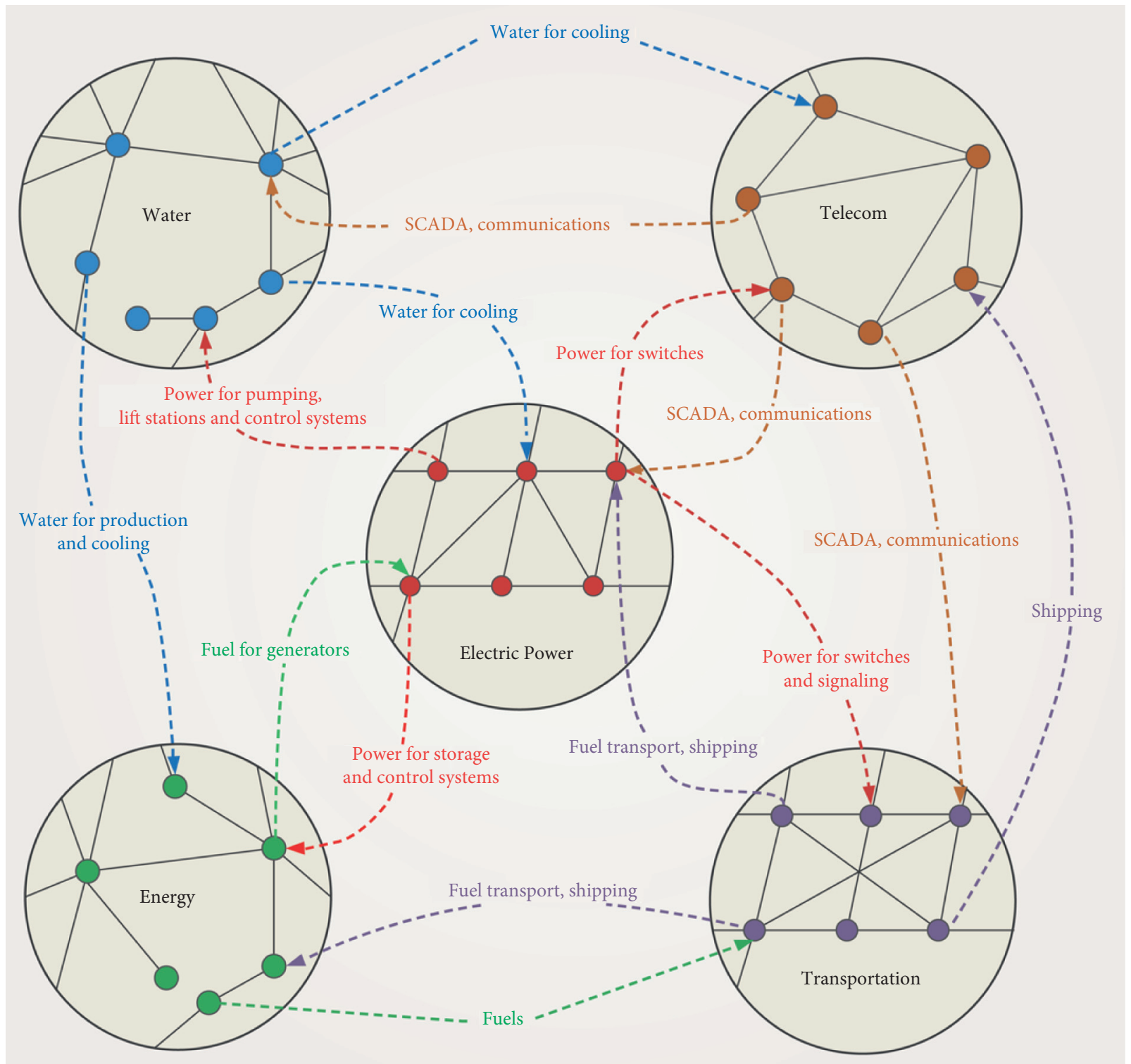

FIGURE 3: Interdependent urban networks. Illustration of complex relationships among different subsystems and infrastructures [119]. Connectivity patterns include feedback and feedforward paths, as well as branching topologies, whose structure and dynamics are better understood within the framework of multilayer systems [102, 103, 105, 106]. Figure reproduced with permission from [120], all rights reserved.

gasoline, the quantity of $\mathrm{CO}_{2}$ emitted, and the relation between area and population of cities [70]. Remarkably, those results highlight the unsustainability of cities whose transportation infrastructure mostly relies upon trafficsensitive modes, despite polycentrism [70]. The feedback between the urban backbone and routing systems is responsible for the emergence of congestion which temporarily degrades the functionality of the city, reminiscent of the slower-is-faster effect [124] and of the Braess's paradox [125], further supporting the hypothesis that a complexity science perspective, at the crossroads of multiple disciplines, is required. Despite its emergent nature, multilayer modeling [126] and analysis $[127,128]$ are enhancing our ability to anticipate congestion phenomena, at least from a theoretical perspective.
As for structure, also urban and interurban dynamics can be understood in terms of interdependent processes. This is the case, for instance, of human movements and epidemics spreading, with integrated models proposed for large-scale mobility [131] between cities, based on different sources of human-generated information, from commuting flows $[132,133]$ to mobile phone data [134-136] and georeferenced social media [137]. Similarly, mobile phone data [138] and credit transactions [78] have been used to model and predict human mobility within a city, showing that predictive performances improve when information about social patterns is accounted for [139-141]. Social multiplexity inferred from the intersection of popular online platforms revealed that users connected on both platforms tend to have more similar neighborhoods, as well as more 
similar social and spatial properties on both platforms with respect to users connected on just one layer [142]. Recently, human flows with recurrent mobility patterns within the city of Medellín in Colombia have been stratified by socioeconomic classes characterizing the city, to unveil the geographic location of patches triggering the epidemic state at the critical point of the process. Remarkably, those patches depend on the social mixing between classes and mobility [129] (see Figure 4). This result is extremely relevant for policy and decision-making, which cannot overlook the knowledge of the conditions under which such types of critical regimes are expected [130].

The analysis of critical properties provides the methodological baseline for understanding and quantifying the resilience of the city. The multiplex structure of London's public transportation network enhances its robustness to random failures of single stations and of entire routes. Analysis of the empirical distribution of check-ins and checks-out shows that passengers travel along fastest paths in a network affected by real disruptions, offering a basis for data-driven policies to enhance the navigability of the city [109]. The spatial constraints play a crucial role for critical properties: in contrast to other systems which are not embedded in space, interdependent urban networks are rather sensitive to failures, and abrupt collapse can be driven by any small fraction of interdependent nodes [143].

Multilayer modeling is therefore fundamental for better understanding city resilience and its complex, interdependent structures and dynamics. Urban ecosystems are, in fact, the result of growing networks which are interconnected and coevolving, inducing strong correlations across layers that can alter their response to social, economic, and environmental processes [144].

\section{An Integrated View of Complex Urban Systems}

3.1. The Cognitive Challenges of Urban Complexity. As already remarked, urban environments are defying not only from the viewpoint of the modeling of urban environments and of their structural interdependencies but also in terms of the challenges they pose to human cognitive systems [145]. For them to be useful, we need to integrate the insights deriving from the analysis of urban dynamics into mental models that enable us to represent, enact, and assess our strategies of navigation, utilization, and governance of the urban space. Such a feature of modeling creates a fascinating parallel with literary fiction [146] and contributes to explaining why narratives have always traditionally been a key tool to conceptualize, represent, and communicate the complexity of urban environments [147]. This is true not only for urban designers and policy-makers but also for local communities and citizens alike. This is why urban cognition is a key frontier of knowledge transmission and application of our findings from research on city complexity.

It has indeed long been recognized that humans have intrinsic cognitive limits in processing information [148]. Given the increasing complexity of highly urbanized cities, such limits have now become a challenge in the interaction of citizens with the urban environment [149]. The concept linking individual experiences to the increasingly complex circumstances of urban life is that of cognitive load [150]. A person's brain can be overloaded when there are too many inputs to reckon with or when sequences of inputs hit so fast that a new input is still being processed when the new one arrives. Under overload, individuals adapt their behavior by changing priorities and recurring to simplifying choice heuristics.

Redefining traditional tools such as maps to deal with the complexity of urban environments is a key step in this process. Recent studies on visual search strategies [151-153] have demonstrated that the time needed to find a route in a transportation network grows with the complexity of its map, with a transition in search strategies from following metro lines to the scattering of eye focus all over the map [152]. A similar transition from directional to isotropic random search has been observed for visual search of hidden objects when one increases the number of distractors [151]. The ability to manage complex "mental maps" is thus limited, and only extensive training on spatial navigation can push this limit with morphological changes in the hippocampus [154]. Therefore, transportation network structures may be too confusing, requiring to wade through too much detail to figure out whether the service is useful [155]. To measure the cognitive load associated with the visual search of a route in transportation networks, an information perspective has been proposed [111] to quantify the difficulty to navigate them. Using a measure of "information search" associated with a trip that goes from one route to another [156], it has been possible to characterize our difficulty to navigate in a public transit map to identify and measure the cognitive limit. To overcome such limits, a "fractal" approach to cartography is in a sense an obvious move, but what is less obvious is the "just in time" adaptive attitude that it commands upon planners, interest groups, and citizens [157].

Transferring these kind of ideas from specialists to nonspecialists is difficult and calls for a profound revision of individual mindsets, not to speak of mental models, and especially so if such knowledge has to become useful and applicable in specific problem-solving contexts [158]. This is an especially burning issue in view of the deliberation processes that support public decision-making in modern democracies. The appeal to oversimplified, and outright incorrect, solutions to complex urban challenges may be especially tempting for politicians and policy-makers when citizens are basically unable to grasp the subtleties of urban policy dilemmas and their implications for their own interests [159]. This can only be balanced by integrating such knowledge into the practical experience and local capability building processes of citizens [160]. But this "pedagogical" change cannot happen without a substantial redefinition of the professional culture of planners and urban experts of all sorts [161].

The ultimate sense of the challenges posed by applying a complexity science perspective to urban systems is that a city is a complex system emerging from the collective behavior of individuals who are themselves complex systems. This 


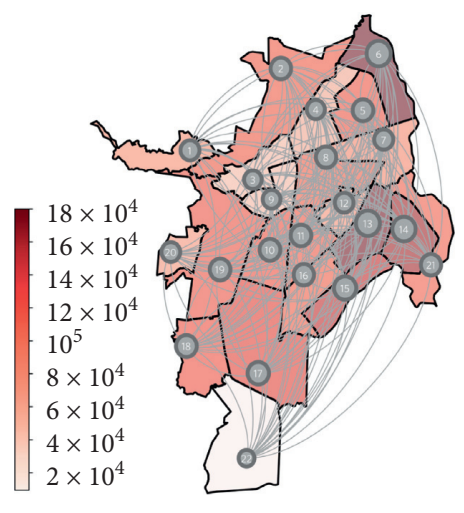

(a)

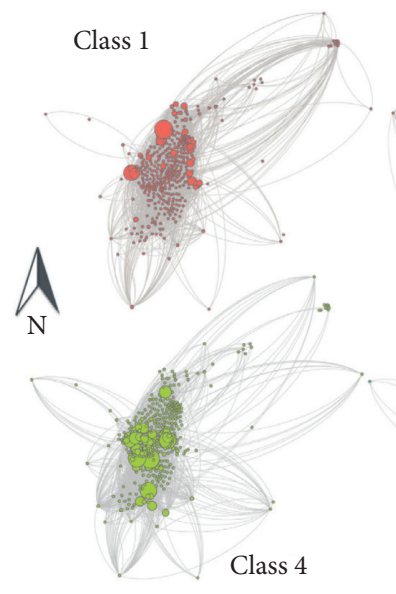

Class 4

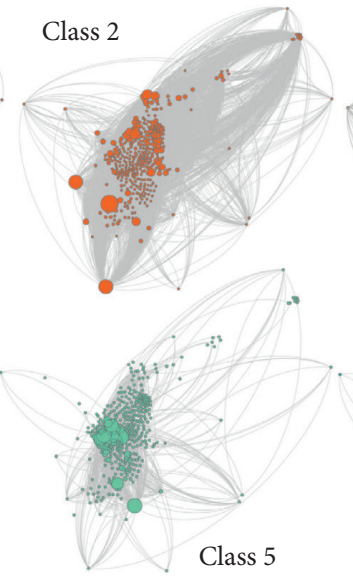

(b)

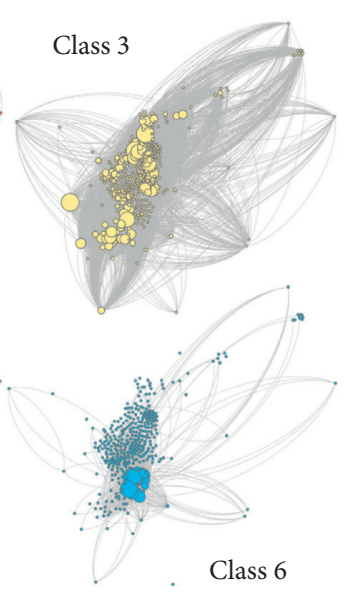

Class 6

Figure 4: Multilayer urban dynamics. (a) Empirical mobility flows among different geographic areas in the city of Cali (Colombia). Each area is modeled as a metapopulation, that is, a node with population dynamics. (b) The city of Medellín (Colombia) stratified with respect to socioeconomic classes. Each class allows to build a layer of a multilayer model of the city, where each metapopulation network encodes human flows of a specific class. Figure reproduced with permission from [129] and [130], all rights reserved.

multiscale complexity feeds back in terms of cognitive constructs into the minds of the very individuals that make it exist [162]. Multiscale complexity is common to all largescale social phenomena, from markets to States to online communities. However, the fact that the city is the sociospatial context that mediates most human experiences makes it especially sensitive and to some extent fundamental to most other forms of social phenomena. Not incidentally, as noted by Portugali [162], Prigogine in his Nobel lecture indicated the city as the natural metaphor of social complexity. In a sense, then, the city's capacity of functioning as a complex system also depends on how the mental representations of the city, elaborated by its inhabitants, influence their own choices and behaviors and how this in turn reflects into certain spatial and behavioral patterns at the macroscale. It is therefore fundamental to think of the city in terms of systems ecology and to develop new ecologically informed models of sociospatial cognition that mediate between the subjective and objective levels of urban experience. This is, for instance, the intuition behind the notion of cognitive affordances as the basis of a complexity-driven urban epistemology: the individual and social capacity to use the city is the result of a contextual negotiation built on previous experience but also sensitive to local variations of the urban codes of meaning [163]. As previous experience with pushing buttons in various different circumstances can guide our choice when we face a button to be possibly pushed in a certain new, unfamiliar circumstance, individuals and communities are getting increasingly familiar with maintaining a style of open-ended adaptive learning [164]. This cognitive fluidity becomes a necessity for citizens facing a constantly shifting and evolving urban environment that can, often unpredictably, challenge their assumptions, play with their perceptions, and put pressure upon their consolidated behavioral repertoires [165]. An affordancesbased approach to urban epistemology can also be usefully tested on the basis of experimental trials with animal cognition, such as in the case of rats [166]. Thinking in terms of affordances creates a natural setting for closing the attitude-action gap that is at the root of the failure of effective collective action in urban environments [167], by repurposing them as "playable" spaces, both individually and collectively [168]. It is by regaining a shared sense of collective intentionality in the urban space that urban selforganization can be both better understood and more effectively governed [169]. But this increased need of a collective awareness calls for a substantial upgrading of our ambition in enabling participative, inclusive practices in the urban space. It is therefore necessary that these goals become a relevant item in the urban policy agenda.

3.2. Planning and Complexity: Adaptive Urban PolicyMaking. From the point of view of planning theory, the main takeaway of a couple of decades' experience of dealing with cities from a complexity-focused perspective is the necessity of a radical redefinition of planning practices as an interplay between institutionally driven design and urban self-organization principles [170]. The stakes are high. Planning practices are mainly justified to secure fair and inclusive access to urban resources. At the same time, cities may look very different when seen from different vantage points corresponding to different levels of benefit and privilege [171]. The consequent danger is that the management of urban complexity may also function as a convenient smokescreen to decline political responsibility and accommodate certain vested interests at the expense of others [172], irrespective of the declared intentions. However, to the contrary, it is also possible that seriously accounting for the self-organization dimension of urban processes into planning practices may function as an enabler of community initiative and active participation [173]. In essence, taking advantage of the lesson of complexity in planning means creating the context for decentralized, 
collaborative action at least as much as prescribing centralized, top-down forms of planning [174], thus laying the premises for a reflexive approach to planning [175].

The real issue from the planning perspective is therefore how to empower citizens and local communities to play an active role in this cocreative process and to be able to conceptualize, promote, and assess collective action in the pursuit of common interests [176] and in the exercise of their right to the city [177]. One possible solution is rediscovering rituals of collective pleasure in public spaces as a foundation for a common social intentionality [178], in the spirit of a repurposed collective action aimed at social change along the lines of Gramscian thinking, consequently turning the urban environment into a "playable" public domain [179]. Many collective practices of public art in the public domain are exploring possibilities and breaking new ground in this direction, by engaging local communities to take an active, propositional attitude towards urban complexity in terms of shared agency and not of passive delegation to planners and high-level stakeholders [180]. In this perspective, we look with great interest at gamificationbased approaches insofar as they are intended not as domesticating formats for passive engagement and manipulative conditioning but rather as a smart deployment of collective resources and talent $[181,182]$ and of selfempowering behavioral change [183], which appeals to expressive rather than to instrumental motives [184]. In this sense, gamification has shown promise as a surprisingly practical and flexible tool to pursue complex technical and sociopolitical collective goals [185], due to two main characteristics: its intrinsic narrative potential and appeal, which as already remarked may effectively function in conveying detailed contextual information in complex urban environments [186], and its endogenous scoring metrics that, while providing direct feedback as to the efficacy of certain individual or collective actions, also build motivation and engagement [187].

In this regard, the pandemic crisis and the consequent necessity to rely upon contact tracing apps to mitigate the spreading of the contagion can be regarded as a missed opportunity. In countries whose local culture is characterized by a strong civic sense and on the emphasis on collective responsibility and duty as well as by a mature stage of the digital transition, such as many Far-Eastern societies $[188,189]$, contract tracing apps have been massively adopted and have functioned well despite the inevitable concerns on privacy [190], keeping the level of contagion and human losses remarkably low [191] if compared to that of more individualistic societies [192] where contract tracing has been implemented relatively late and dedicated apps have been adopted by a minority [192]. Even in a situation of high personal risk, reliance on responsibility and fear as incentives to app adoption has not proven effective in mobilizing citizens to behave prosocially, despite a generalized declared willingness to download contact tracing apps across most countries [193]. On the other hand, the apps themselves were merely designed, following a purely functional logic, as carriers of information and control devices in a moment in which people felt a sudden, heavy burden from the almost complete disruption of their previous social life. Maybe considering social incentives to communication and exchange that were put particularly under stress during the pandemic crisis could have been a key to a stronger motivation to adopt the app by choosing suitable, motivationally salient cues. For instance, people could be shown how the probability of lifting up social restrictions would be affected by the rate of adoption of the app and consequently how that probability could change for every extra thousand people adopting it, inviting them to contribute by adopting the app themselves and convincing their acquaintances to do the same. Or, alternatively, in terms of appeal to responsibility, people could receive a constantly updated estimate of the probability to be infectious given their history of social contacts, so as to discourage risky behavior through appeal to regret [194].

\section{Outlooks}

Most applications of complexity science to urban issues tend to focus, for understandable reasons, on specific dimensions of the urban environment. Clearly, studying the structure and the dynamical evolution of urban utilities networks, transportation systems, or resource flows is already more than enough to challenge our modeling abilities. However, if we want to fully acknowledge the implications of the previous analysis and in particular the necessity of integrating the three dimensions of modeling, cognition, and governance, we need to look at urban environments not from a sector-specific but from a system-wide perspective that cuts across different sectors and dimensions of the urban fabric. Such an integrated framework to understand cities through data-powered tools sits at the edge between many different disciplines such as statistical physics, social sciences, economics, digital health and wellbeing, and engineering, to name only a few ones. The state-of-the-art applications reviewed above provide us with a promising benchmark by characterizing urban complexity in terms of multiplex networks and possibly point to the multiplex city as a computationally appropriate and conceptually scalable [195] representation of urban complexity [196], which will allow the development and deployment of new urban governance strategies, as well as the redesign of old ones [54].

Urban environments clearly raise specific health issues, which are becoming of increasing relevance once we are reminded that, according to recent estimations, up to $70 \%$ of the world's population will be living in urban areas by 2050 [197], and even if in the postpandemic scenario this trend could be subject to changes in the medium-long term, cities will inevitably keep on playing a pivotal role in future economies and societies [198]. This extraordinary scale of urbanization is affecting both the environmental impact of human activities and the nature and scope of human health and wellbeing issues by posing new adaptive challenges [199]. The Ottawa global health milestones agreement Charter puts the concept of the promotion of healthy practices and lifestyles at the center of a socially and financially sustainable approach to public health [200], where, as formalized by the salutogenesis [215] paradigm [201], the 
focus shifts from the causes and reinforcing conditions of diseases to those that favor and preserve health. The crucial step that enables individuals to successfully adapt to the stressful conditions of the urban environments of socioeconomically advanced societies is to enhance their capacity to cope with such critical factors by improving resilience at all social scales [202]. The urban dimension of salutogenesis clearly becomes all the more central in the postpandemic scenario and will likely leave a deep trace in future urban policies [203].

Although these principles are today widely recognized, finding viable approaches to their implementation in urban environments is not easy task. However, a clever use of the incentive systems connected to digital participation may provide, as discussed above, an innovative platform to motivate people to pursue healthy habits and lifestyles while promoting other public interest goals at the same time. To address this issue, it is crucial to devise data-driven solutions for the promotion of innovative practices of urban health and wellbeing to promote a salutogenic approach to urban space through proactive access to, and use of, the varied mix of wellbeing-enhancing assets in the public domain. Such promotion may be accomplished by means of gamified participatory practices which deeply engage people in the active pursuit of integrated salutogenic goals [204, 205].

Strategies to encourage citizens to pursue health promotion goals by actively engaging with their urban environment include the following:

(i) Fostering inclusiveness and relationship building instead of social stratification and segregation [206]

(ii) Promoting cultural participation by arousing curiosity about, and involvement with, urban cultural heritage and poorly known landmarks [207]

(iii) Creating new opportunities to adopt healthy habits, including increased mobility, while reducing depletion of natural capital [208, 209]

To understand to what extent an integrated approach that takes culture as a driver of urban change may become a powerful basis for a systemic view of urban functioning and change which invites citizens to be proactive in the pursuit of their own quality of life and wellbeing, two aspects of special importance are sociability and cultural experience. Sociability is an issue of increasing relevance in the public health agenda, as loneliness is now recognized as a serious public health problem [210]. Cultural experience is increasingly connected to health and wellbeing issues by a rapidly growing literature $[211,212]$. The eudaimonic [216] approach to wellbeing provides a conceptual framework encompassing all three dimensions within the overarching salutogenic framework, as it postulates that a harmonic integration of different spheres of human existence best fits human sociopsychological development [213] and promotes health more effectively than narrower approaches [214]. In an eudaimonic perspective, the urban environment becomes an extremely rich and potentially stimulating playground on multiple dimensions: as a natural context for urban mobility, as an elective space of sociability, and as a theater of cultural experiences. Breathing new life into the postpandemic urban fabric will be not only a problem of technical efficiency and of provision of adequate services tailored to the new social demands and needs but also an exercise of collective sensemaking. In the forthcoming scenario, it will therefore be crucial to directly involve citizens in collective problemsolving processes to codesign the postpandemic city, both to build upon collective intelligence and to rebuild social cohesion after a long, critical period of isolation and social alienation and as a powerful driver of widespread adoption of prosocial practices, attitudes, and new habits without which the cities of the future might become less and less livable. This is in particular true in view of the strong call that urban life in postpandemic cities will make for widespread citizens' responsibility and attention to safety concerns and public health norms compliance. Taking this forced start of a new urban cycle as an opportunity to bring urban sociability at the core of urban policies through the active contribution of citizens may lead to new, emergent forms of social cooperation whose collective benefits may be directly measured and, consequently, may further reinforce individual and social motivations to pursue a more sustainable, cohesive route to urban development. It is unlikely that the new challenges will be effectively tackled through businessas-usual policy approaches [2], and there will be the need to refresh what looked like the "default" conviction only one year ago, namely, that cities are the undisputed, trend-setting centers of gravity of social, economic, and cultural life. With the increasing diffusion of remote smart working, the choice to live in a city will be less instrumental and will have to be motivated by the intrinsic richness of opportunity of the urban environment as to the promotion of socially rewarding encounters and mind-opening, stimulating experiences. In the postpandemic scenario, sociability habits and patterns in the urban space will have to be rebuilt almost from scratch, and new demands for social connection and meaningful interaction will inevitably arise. Likewise, the postpandemic city will have to rethink and repurpose its public space as a theater of collective expression and inspiration. We need to be ready to tackle these challenges through a clear vision of the multilayered complexity of urban dynamics, with a strong focus on the livability and liveliness of urban environments. However important, these dimensions of sense-making have been marginally dealt with by complexity models and analyses. The time has come to integrate them into a full-fledged approach to urban systems.

\section{Data Availability}

No data were used to support this study.

\section{Conflicts of Interest}

The authors declare that they have no conflicts of interest.

\section{Authors' Contributions}

All authors equally contributed to this work. 


\section{References}

[1] J. JacobsVintage, New York, NY, USA, 1992.

[2] J. C. Scott, Seeing like a State: How Certain Schemes to Improve the Human Condition Have Failed, Yale University Press, New Haven, USA, 2020.

[3] C. Alexanderp. 1965, 1964.

[4] C. Alexander, A City Is Not a Tree, Sustasis Press/Off the Common Books, Amsterdam, Holland, 2017.

[5] C. Alexander, A Pattern Language: Towns, Buildings, Construction, Oxford University Press, Oxford, UK, 1977.

[6] C. Alexander, The Timeless Way of Building, Vol. 1, Oxford University Press, New York, NY, USA, 1979.

[7] C. Alexander, "The phenomenon of life: book one the nature of order: an essay on the art of building and the nature of the universe," in A Vision of a Living World: The Nature of Order, Book 3, Center for Environmental Structure, New York, NY, USA, 2002.

[8] C. Alexander, The Process of Creating Life, Vol. 10, Center for Environmental Structure, Berkeley, CA, 2002.

[9] C. Alexander, A Vision of a Living World: The Nature of Order, Book 3, Center for Environmental Structure, New York, NY, USA, 2004.

[10] C. Alexander, The Luminous Ground: An Essay on the Art of Building and the Nature of the Universe, Taylor \& Francis, Milton Park, UK, 2004.

[11] G. Stiny, "Introduction to shape and shape grammars," Environment and Planning B: Planning and Design, vol. 7, no. 3, pp. 343-351, 1980.

[12] K. Karimi, "A configurational approach to analytical urban design: 'Space syntax' methodology," Urban Design International, vol. 17, no. 4, pp. 297-318, 2012.

[13] T. V. Heitor, J. P. Duarte, and R. M. Pinto, "Combing grammars and space syntax: formulating, generating and evaluating designs," International Journal of Architectural Computing, vol. 2, no. 4, pp. 491-515, 2004.

[14] P. M. Allen and M. Sanglier, "Urban evolution, self-organization, and decisionmaking," Environment \& Planning A: Economy and Space, vol. 13, no. 2, pp. 167-183, 1981.

[15] D. S. Dendrinos and H. Mullally, Urban Evolution: Studies in the Mathematical Ecology of Cities, Oxford University Press, Oxford, USA, 1985.

[16] M. Batty and P. A. Longley, Fractal Cities: A Geometry of Form and Function, Academic Press, Cambridge, Massachusetts, USA, 1994.

[17] I. Benenson, "Multi-agent simulations of residential dynamics in the city," Computers, Environment and Urban Systems, vol. 22, no. 1, pp. 25-42, 1998.

[18] M. Batty, Y. Xie, and Z. Sun, "Modeling urban dynamics through GIS-based cellular automata," Computers, Environment and Urban Systems, vol. 23, no. 3, pp. 205-233, 1999.

[19] M. Batty and P. M. Torrens, "Modelling and prediction in a complex world," Futures, vol. 37, no. 7, pp. 745-766, 2005.

[20] M. Barthelemy, The Structure and Dynamics of Cities, Cambridge University Press, Cambridge, USA, 2016.

[21] M. Barthelemy, "The statistical physics of cities," Nature Reviews Physics, vol. 1, no. 6, pp. 406-415, 2019.

[22] H. Lu and Y. Shi, "Complexity of public transport networks," Tsinghua Science \& Technology, vol. 12, no. 2, pp. 204-213, 2007.

[23] M. Zarghami and S. Akbariyeh, "System dynamics modeling for complex urban water systems: application to the city of
Tabriz, Iran," Resources, Conservation and Recycling, vol. 60, pp. 99-106, 2012.

[24] Y. Zhang, Z. Yang, B. D. Fath, and S. Li, "Ecological network analysis of an urban energy metabolic system: model development, and a case study of four Chinese cities," Ecological Modelling, vol. 221, no. 16, pp. 1865-1879, 2010.

[25] S. Kai, L. Chun-Qiong, and L. Si-Chuan, "Self-Organized Criticality: emergent complex behavior in PM10 pollution," International Journal of Atmospheric Sciences, vol. 2013, Article ID 419694, 7 pages, 2013.

[26] M. Fonoberova, V. A. Fonoberov, I. Mezic, J. Mezic, and P. J. Brantingham, "Crime and violence in urban settings," The Journal of Artificial Societies and Social Simulation, vol. 15, p. 2, 2012.

[27] K. M. Faust, D. M. Abraham, and D. DeLaurentis, "Coupled human and water infrastructure systems sector interdependencies: framework evaluating the impact of cities experiencing urban decline," Journal of Water Resources Planning and Management, vol. 143, no. 8, Article ID 04017043, 2017.

[28] L. M. A. Bettencourt, J. Lobo, D. Strumsky, and G. B. West, "Urban scaling and its deviations: revealing the structure of wealth, innovation and crime across cities," PLoS One, vol. 5, no. 11, Article ID e13541, 2010.

[29] J. Johnson, A. Nowak, P. Ormerod, B. Rosewell, and Y.-C. Zhang, Non-Equilibrium Social Science and Policy: Introduction and Essays on New and Changing Paradigms in Socio-Economic Thinking, Springer, Berlin, Germany, 2017.

[30] B. Lepri, F. Antonelli, F. Pianesi, and A. Pentland, "Making big data work: smart, sustainable, and safe cities," EPJ Data Science, vol. 4, p. 1, 2015.

[31] M. Lenormand, T. Louail, M. Barthelemy, and J. Ramasco, Spatial Accuracy 2016, 2016.

[32] R. Gallotti, R. Louf, J.-M. Luck, and M. Barthelemy, "Tracking random walks," Journal of The Royal Society Interface, vol. 15, no. 139, 2018.

[33] M. Batty, The New Science of Cities, MIT Press, Cambridge, USA, 2013.

[34] E. N. Gilbert, "Random plane networks," Journal of the Society for Industrial and Applied Mathematics, vol. 9, no. 4, pp. 533-543, 1961.

[35] R. Gallotti, G. Bertagnolli, and M. De Domenico, EPJ Data Science, vol. 10, p. 1, 2021.

[36] M. Barthélemy, "Spatial networks," Physics Reports, vol. 499, no. 1-3, pp. 1-101, 2011.

[37] V. Latora and M. Marchiori, "Efficient behavior of smallworld networks," Physical Review Letters, vol. 87, no. 19, 2001.

[38] C. Andersson, K. Frenken, and A. Hellervik, "A complex network approach to urban growth," Environment \& Planning A: Economy and Space, vol. 38, no. 10, pp. 19411964, 2006.

[39] S. Porta, P. Crucitti, and V. Latora, "The network analysis of urban streets: a dual approach," Physica A: Statistical Mechanics and its Applications, vol. 369, no. 2, pp. 853-866, 2006.

[40] C. Zhong, S. M. Arisona, X. Huang, M. Batty, and G. Schmitt, "Detecting the dynamics of urban structure through spatial network analysis," International Journal of Geographical Information Science, vol. 28, no. 11, pp. 2178-2199, 2014.

[41] A. Sevtsuk and M. Mekonnen, "Urban network analysis. A new toolbox for ArcGIS," Revue Internationale de Géomatique, vol. 22, no. 2, pp. 287-305, 2012. 
[42] Y.-H. Tsai, "Quantifying urban form: compactness versus 'sprawl'," Urban Studies, vol. 42, no. 1, pp. 141-161, 2005.

[43] M. Guérois and D. Pumain, "Built-up encroachment and the urban field: a comparison of forty European cities," Environment \& Planning A: Economy and Space, vol. 40, no. 9, pp. 2186-2203, 2008.

[44] N. Schwarz, "Urban form revisited-selecting indicators for characterising European cities," Landscape and Urban Planning, vol. 96, no. 1, pp. 29-47, 2010.

[45] C. K. Gately, L. R. Hutyra, and I. Sue Wing, "Cities, traffic, and CO2: a multidecadal assessment of trends, drivers, and scaling relationships," Proceedings of the National Academy of Sciences, vol. 112, no. 16, pp. 4999-5004, 2015.

[46] R. Ewing and S. Hamidi, "Compactness versus sprawl," Journal of Planning Literature, vol. 30, no. 4, pp. 413-432, 2015.

[47] C. Song, T. Koren, P. Wang, and A.-L. Barabási, "Modelling the scaling properties of human mobility," Nature Physics, vol. 6, no. 10, pp. 818-823, 2010.

[48] T. Louail, M. Lenormand, M. Picornell et al., "Uncovering the spatial structure of mobility networks," Nature Communications, vol. 6, no. 1, 2015.

[49] R. Gallotti, A. Bazzani, S. Rambaldi, and M. Barthelemy, "A stochastic model of randomly accelerated walkers for human mobility," Nature Communications, vol. 7, 2016.

[50] H. Barbosa, M. Barthelemy, G. Ghoshal et al., "Human mobility: models and applications," Physics Reports, vol. 734, pp. 1-74, 2018.

[51] D. Helbing, "Traffic and related self-driven many-particle systems," Reviews of Modern Physics, vol. 73, no. 4, pp. 1067-1141, 2001.

[52] D. Li, B. Fu, Y. Wang et al., "Percolation transition in dynamical traffic network with evolving critical bottlenecks," Proceedings of the National Academy of Sciences, vol. 112, no. 3, pp. 669-672, 2015.

[53] S. Çolak, A. Lima, and M. C. González, "Understanding congested travel in urban areas," Nature Communications, vol. 7, 2016.

[54] A. Solé-Ribalta, S. Gómez, and A. Arenas, "Decongestion of urban areas with hotspot pricing," Networks and Spatial Economics, vol. 18, no. 1, pp. 33-50, 2018.

[55] J. Depersin and M. Barthelemy, "From global scaling to the dynamics of individual cities," Proceedings of the National Academy of Sciences, vol. 115, no. 10, pp. 2317-2322, 2018.

[56] F. Le Néchet, "Cybergeo," European Journal of Geography, 2012.

[57] B. Stone, "Urban sprawl and air quality in large US cities," Journal of Environmental Management, vol. 86, no. 4, pp. 688-698, 2008.

[58] E. Uherek, T. Halenka, J. Borken-Kleefeld et al., "Transport impacts on atmosphere and climate: land transport," Atmospheric Environment, vol. 44, no. 37, pp. 4772-4816, 2010.

[59] A. Martilli, "An idealized study of city structure, urban climate, energy consumption, and air quality," Urban Climate, vol. 10, pp. 430-446, 2014.

[60] R. Ewing, G. Meakins, S. Hamidi, and A. C. Nelson, "Relationship between urban sprawl and physical activity, obesity, and morbidity-update and refinement," Health \& Place, vol. 26, pp. 118-126, 2014.

[61] D. E. Newby, P. M. Mannucci, G. S. Tell et al., "Expert position paper on air pollution and cardiovascular disease," European Heart Journal, vol. 36, no. 2, pp. 83-93, 2014.

[62] M. B. Rice, P. L. Ljungman, E. H. Wilker et al., "Long-term exposure to traffic emissions and fine particulate matter and lung function decline in the framingham heart study," American Journal of Respiratory and Critical Care Medicine, vol. 191, no. 6, pp. 656-664, 2015.

[63] W. Li, K. S. Dorans, E. H. Wilker et al., "Residential proximity to major roadways, fine particulate matter, and hepatic steatosis," American Journal of Epidemiology, vol. 186, no. 7, pp. 857-865, 2017.

[64] J. Nicholl, J. West, S. Goodacre, and J. Turner, "The relationship between distance to hospital and patient mortality in emergencies: an observational study," Emergency Medicine Journal, vol. 24, no. 9, pp. 665-668, 2007.

[65] L. M. A. Bettencourt, J. Lobo, D. Helbing, C. Kühnert, and G. B. West, "Growth, innovation, scaling, and the pace of life in cities," Proceedings of the National Academy of Sciences, vol. 104, no. 17, pp. 7301-7306, 2007.

[66] L. M. A. Bettencourt, "The origins of scaling in cities," Science, vol. 340, no. 6139, pp. 1438-1441, 2013.

[67] A. Bertaud, 2004.

[68] V. Volpati and M. Barthelemy, "The spatial organization of the population density in cities," 2018, http://arxiv.org/abs/ 1804.00855 .

[69] R. Louf and M. Barthelemy, "Modeling the polycentric transition of cities," Physical Review Letters, vol. 111, no. 19, 2013.

[70] R. Louf and M. Barthelemy, "How congestion shapes cities: from mobility patterns to scaling," Scientific Reports, vol. 4, no. 1, 2014.

[71] M. Haklay and P. Weber, "OpenStreetMap: user-generated street maps," IEEE Pervasive Computing, vol. 7, no. 4, pp. $12-18,2008$.

[72] P. Neis, D. Zielstra, and A. Zipf, “The street network evolution of crowdsourced maps: OpenStreetMap in Germany 2007-2011," Future Internet, vol. 4, no. 1, pp. 1-21, 2011.

[73] C. Ratti, D. Frenchman, R. M. Pulselli, and S. Williams, "Mobile landscapes: using location data from cell phones for urban analysis," Environment and Planning B: Planning and Design, vol. 33, no. 5, pp. 727-748, 2006.

[74] M. C. González, C. A. Hidalgo, and A.-L. Barabási, "Understanding individual human mobility patterns," Nature, vol. 453, no. 7196, pp. 779-782, 2008.

[75] C. Song, Z. Qu, N. Blumm, and A.-L. Barabasi, "Limits of predictability in human mobility," Science, vol. 327, no. 5968, pp. 1018-1021, 2010.

[76] V. Soto and E. Frías-martínez, "Robust land use characterization of urban landscapes using cell phone data," 2011.

[77] T. Louail, M. Lenormand, O. G. C. Ros et al., "From mobile phone data to the spatial structure of cities," Scientific Reports, vol. 4, 2014.

[78] S. Hasan, C. M. Schneider, S. V. Ukkusuri, and M. C. González, "Spatiotemporal patterns of urban human mobility," Journal of Statistical Physics, vol. 151, no. 1-2, pp. 304-318, 2012.

[79] L. Jánošíková, J. Slavík, and M. Koháni, "Estimation of a route choice model for urban public transport using smart card data," Transportation Planning and Technology, vol. 37, p. 638, 2014.

[80] S. Sobolevsky, I. Bojic, A. Belyi et al. in Proceedings of the 2015 IEEE International Congress on Big Data, June 2015.

[81] M. Lenormand, T. Louail, O. G. Cantú-Ros et al., "Influence of sociodemographic characteristics on human mobility," Scientific Reports, vol. 5, no. 1, 2015.

[82] M. K. El Mahrsi, E. Come, L. Oukhellou, and M. Verleysen, "Clustering smart card data for urban mobility analysis," 
IEEE Transactions on Intelligent Transportation Systems, vol. 18, no. 3, pp. 712-728, 2017.

[83] R. Di Clemente, M. Luengo-Oroz, M. Travizano, S. Xu, B. Vaitla, and M. C. González, "Sequences of purchases in credit card data reveal lifestyles in urban populations," Nature Communications, vol. 9, no. 1, 2018.

[84] Y. Zheng, Q. Li, Y. Chen, X. Xie, and W.-Y. Ma, "Understanding mobility based on GPS data," in Proceedings of the 10th International Conference on Ubiquitous ComputingUbiComp'08., pp. 312-321, ACM, Seoul, Korea, September 2008.

[85] A. Bazzani, B. Giorgini, S. Rambaldi, R. Gallotti, and L. Giovannini, "Statistical laws in urban mobility from microscopic GPS data in the area of florence," Journal of Statistical Mechanics: Theory and Experiment, vol. 2010, no. $05,2010$.

[86] R. Gallotti, A. Bazzani, and S. Rambaldi, "Towards a statistical physics of human mobility," International Journal of Modern Physics C, vol. 23, 2012.

[87] R. Gallotti, A. Bazzani, and S. Rambaldi, "Understanding the variability of daily travel-time expenditures using GPS trajectory data," EPJ Data Science, vol. 4, no. 1, p. 18, 2015.

[88] L. Pappalardo, F. Simini, S. Rinzivillo, D. Pedreschi, F. Giannotti, and A.-L. Barabási, "Returners and explorers dichotomy in human mobility," Nature Communications, vol. 6, no. 1, 2015.

[89] F. Kling and A. Pozdnoukhov, "When a city tells a story," in Proceedings of the 20th International Conference on Advances in Geographic Information Systems-SIGSPATIAL12, 2012.

[90] A. Noulas, S. Scellato, R. Lambiotte, M. Pontil, and C. Mascolo, "A tale of many cities: universal patterns in human urban mobility," PLoS One, vol. 7, no. 5, Article ID e37027, 2012.

[91] T. H. Silva, P. O. S. V. de Melo, J. M. Almeida, J. Salles, and A. A. F. Loureiro, "A comparison of foursquare and instagram to the study of city dynamics and urban social behavior," in Proceedings of the 2nd ACM SIGKDD International Workshop on Urban Computing-UrbComp 13, August 2013.

[92] A. Noulas, C. Mascolo, and E. Frias-Martinez, "Exploiting foursquare and cellular data to infer user activity in urban environments," in Proceedings of the 2013 IEEE 14th International Conference on Mobile Data Management, June 2013.

[93] R. Feick and C. Robertson, "A multi-scale approach to exploring urban places in geotagged photographs," Computers, Environment and Urban Systems, vol. 53, pp. 96-109, 2015.

[94] T. Shelton, A. Poorthuis, and M. Zook, "Social media and the city: rethinking urban socio-spatial inequality using usergenerated geographic information," Landscape and Urban Planning, vol. 142, pp. 198-211, 2015.

[95] E. Chaniotakis and C. Antoniou, "Use of geotagged social media in urban settings: empirical evidence on its potential from twitter," in Proceedings of the 2015 IEEE 18th International Conference on Intelligent Transportation Systems, September 2015.

[96] Y. Hu, S. Gao, K. Janowicz, B. Yu, W. Li, and S. Prasad, "Extracting and understanding urban areas of interest using geotagged photos," Computers, Environment and Urban Systems, vol. 54, pp. 240-254, 2015.

[97] G. Lansley and P. A. Longley, "The geography of Twitter topics in London," Computers, Environment and Urban Systems, vol. 58, pp. 85-96, 2016.
[98] S. Cvetojevic, L. Juhasz, and H. Hochmair, "Positional accuracy of twitter and instagram images in urban environments," GI_Forum, vol. 4, no. 1, pp. 191-203, 2016.

[99] J. D. Boy and J. Uitermark, "How to study the city on instagram," PLoS One, vol. 11, no. 6, Article ID e0158161, 2016.

[100] P. Giridhar, S. Wang, T. Abdelzaher, R. Ganti, L. Kaplan, and J. George, "On localizing urban events with instagram," in Proceedings of the IEEE INFOCOM 2017-IEEE Conference on Computer Communications, May 2017.

[101] T. R. Meyer, D. Balagué, M. Camacho-Collados et al., “A year in Madrid as described through the analysis of geotagged twitter data," Environment and Planning B: Urban Analytics and City Science, vol. 46, no. 9, pp. 1724-1740, 2018.

[102] M. De Domenico, A. Solé-Ribalta, E. Cozzo et al., "Mathematical formulation of multilayer networks," Physical Review X, vol. 3, no. 2, Article ID 041022, 2013.

[103] M. Kivelä, A. Arenas, M. Barthelemy, J. P. Gleeson, Y. Moreno, and M. A. Porter, "Multilayer networks," Journal of complex networks, vol. 2, no. 3, pp. 203-271, 2014.

[104] R. Gallotti and M. Barthelemy, "Anatomy and efficiency of urban multimodal mobility," Scientific Reports, vol. 4, no. 1, 2014.

[105] S. V. Buldyrev, R. Parshani, G. Paul, H. E. Stanley, and S. Havlin, "Catastrophic cascade of failures in interdependent networks," Nature, vol. 464, no. 7291, pp. 1025-1028, 2010.

[106] J. Gao, S. V. Buldyrev, H. E. Stanley, and S. Havlin, "Networks formed from interdependent networks," Nature Physics, vol. 8, no. 1, pp. 40-48, 2012.

[107] R. Gallotti and M. Barthelemy, "The multilayer temporal network of public transport in Great Britain," Scientific Data, vol. 2, no. 1, 2015.

[108] R. G. Morris and M. Barthelemy, "Transport on coupled spatial networks," Physical Review Letters, vol. 109, no. 12, 2012.

[109] M. De Domenico, A. Solé-Ribalta, S. Gómez, and A. Arenas, "Navigability of interconnected networks under random failures," Proceedings of the National Academy of Sciences, vol. 111, no. 23, pp. 8351-8356, 2014.

[110] L. Alessandretti, M. Karsai, and L. Gauvin, "User-based representation of time-resolved multimodal public transportation networks," Royal Society Open Science, vol. 3, no. 7, 2016.

[111] R. Gallotti, M. A. Porter, and M. Barthelemy, "Lost in transportation: information measures and cognitive limits in multilayer navigation," Science Advances, vol. 2, no. 2, Article ID e1500445, 2016.

[112] A. Aleta, S. Meloni, and Y. Moreno, "A Multilayer perspective for the analysis of urban transportation systems," Scientific Reports, vol. 7, no. 1, p. 44359, 2017.

[113] M. De Domenico, V. Nicosia, A. Arenas, and V. Latora, "Structural reducibility of multilayer networks," Nature Communications, vol. 6, no. 1, p. 6864, 2015.

[114] E. Cozzo, M. Kivelä, M. D. Domenico et al., "Structure of triadic relations in multiplex networks," New Journal of Physics, vol. 17, no. 7, Article ID 073029, 2015.

[115] E. Strano, S. Shai, S. Dobson, and M. Barthelemy, "Multiplex networks in metropolitan areas: generic features and local effects," Journal of The Royal Society Interface, vol. 12, no. $111,2015$.

[116] M. C. González, C. A. Hidalgo, and A.-L. Barabási, "Understanding individual human mobility patterns," Nature, vol. 453, no. 7196, pp. 779-782, 2008. 
[117] C. M. Schneider, V. Belik, T. Couronné, Z. Smoreda, and M. C. González, "Unravelling daily human mobility motifs," Journal of The Royal Society Interface, vol. 10, no. 84, 2013.

[118] C. G. Prato, "Route choice modeling: past, present and future research directions," Journal of Choice Modelling, vol. 2, no. 1, pp. 65-100, 2009.

[119] S. M. Rinaldi, J. P. Peerenboom, and T. K. Kelly, "Identifying, understanding, and analyzing critical infrastructure interdependencies," IEEE Control Systems Magazine, vol. 21, no. 11, 2001.

[120] J. Gao, D. Li, and S. Havlin, "From a single network to a network of networks," National Science Review, vol. 1, no. 3, pp. 346-356, 2014.

[121] J. G. Wardrop and J. I. Whitehead, "Correspondence. Some theoretical aspects of road traffic research," ProceedingsInstitution of Civil Engineers, vol. 1, no. 5, pp. 767-768, 1952.

[122] A. Lima, R. Stanojevic, D. Papagiannaki, P. Rodriguez, and M. C. González, "Understanding individual routing behaviour," Journal of the Royal Society Interface, vol. 13, no. $116,2016$.

[123] M. De Domenico, A. Lima, M. C. González, and A. Arenas, "Personalized routing for multitudes in smart cities," EPJ Data Science, vol. 4, no. 1, p. 1, 2015.

[124] C. Gershenson and D. Helbing, "When slower is faster," Complexity, vol. 21, no. 2, pp. 9-15, 2015.

[125] D. Braess, "Über ein Paradoxon aus der Verkehrsplanung," Unternehmensforschung Operations Research - Recherche Opérationnelle, vol. 12, no. 1, pp. 258-268, 1968.

[126] A. Solé-Ribalta, S. Gómez, and A. Arenas, "Congestion induced by the structure of multiplex networks," Physical Review Letters, vol. 116, no. 10, 2016.

[127] M. De Domenico, A. Solé-Ribalta, E. Omodei, S. Gómez, and A. Arenas, "Ranking in interconnected multilayer networks reveals versatile nodes," Nature Communications, vol. 6, no. 1, p. 6868, 2015.

[128] S. Manfredi, E. Di Tucci, and V. Latora, "Mobility and congestion in dynamical multilayer networks with finite storage capacity," Physical Review Letters, vol. 120, 2018.

[129] D. Soriano-Paños, L. Lotero, A. Arenas, and J. GómezGardeñes, "Spreading processes in multiplex metapopulations containing different mobility networks," Physical Review X, vol. 8, 2018.

[130] J. Gómez-Gardeñes, D. Soriano-Paños, and A. Arenas, "Critical regimes driven by recurrent mobility patterns of reaction-diffusion processes in networks," Nature Physics, vol. 14, no. 4, pp. 391-395, 2018.

[131] V. Belik, T. Geisel, and D. Brockmann, "Natural human mobility patterns and spatial spread of infectious diseases," Physical Review X, vol. 1, 2011.

[132] D. Balcan, V. Colizza, B. Goncalves, H. Hu, J. J. Ramasco, and A. Vespignani, "Multiscale mobility networks and the spatial spreading of infectious diseases," Proceedings of the National Academy of Sciences, vol. 106, no. 51, pp. 2148421489, 2009.

[133] D. Brockmann and D. Helbing, "The hidden geometry of complex, network-driven contagion phenomena," Science, vol. 342, no. 6164, pp. 1337-1342, 2013.

[134] A. Lima, M. De Domenico, V. Pejovic, and M. Musolesi, Scientific Reports, vol. 5, 2015.

[135] J. T. Matamalas, M. De Domenico, and A. Arenas, “Assessing reliable human mobility patterns from higher order memory in mobile communications," Journal of The Royal Society Interface, vol. 13, no. 121, 2016.
[136] P. Bosetti, P. Poletti, M. Stella, B. Lepri, S. Merler, and M. De Domenico, "Reducing measles risk in turkey through social integration of syrian refugees," 2019, http://arxiv.org/ abs/1901.04214.

[137] B. Hawelka, I. Sitko, E. Beinat, S. Sobolevsky, P. Kazakopoulos, and C. Ratti, "Geo-located Twitter as proxy for global mobility patterns," Cartography and Geographic Information Science, vol. 41, no. 3, pp. 260-271, 2014.

[138] X.-Y. Yan, C. Zhao, Y. Fan, Z. Di, and W.-X. Wang, "Universal predictability of mobility patterns in cities," Journal of The Royal Society Interface, vol. 11, no. 100, 2014.

[139] E. Cho, S. A. Myers, and J. Leskovec, "Friendship and mobility," in Proceedings of the 17th ACM SIGKDD International Conference on Knowledge Discovery and Data Mining, 2011.

[140] M. De Domenico, A. Lima, and M. Musolesi, "Interdependence and predictability of human mobility and social interactions," Pervasive and Mobile Computing, vol. 9, no. 6, pp. 798-807, 2013.

[141] J. L. Toole, C. Herrera-Yaqüe, C. M. Schneider, and M. C. González, "Coupling human mobility and social ties," Journal of the Royal Society Interface, vol. 12, no. 105, 2015.

[142] D. Hristova, A. Noulas, C. Brown, M. Musolesi, and C. Mascolo, "A multilayer approach to multiplexity and link prediction in online geo-social networks," EPJ Data Science, vol. 5, no. 1, p. 24, 2016.

[143] A. Bashan, Y. Berezin, S. V. Buldyrev, and S. Havlin, "The extreme vulnerability of interdependent spatially embedded networks," Nature Physics, vol. 9, no. 10, pp. 667-672, 2013.

[144] J. Y. Kim and K.-I. Goh, "Coevolution and correlated multiplexity in multiplex networks," Physical Review Letters, vol. 111, no. 5, 2013.

[145] J. Portugali, Complexity, Cognition and the City, Springer Science \& Business Media, Berlin, Germany, 2011.

[146] R. Frigg, "Models and fiction," Synthese, vol. 172, no. 2, pp. 251-268, 2010.

[147] V. Mukhija, "Learning from invisible cities: the interplay and dialogue of order and disorder," Environment \& Planning A: Economy and Space, vol. 47, no. 4, pp. 801-815, 2015.

[148] G. A. Miller, "The magical number seven, plus or minus two: some limits on our capacity for processing information," Psychological Review, vol. 63, no. 2, pp. 81-97, 1956.

[149] S. Milgram, "The experience of living in cities," Science, vol. 167, no. 3924, pp. 1461-1468, 1970.

[150] F. Paas, J. E. Tuovinen, H. Tabbers, and P. W. M. Van Gerven, "Cognitive load measurement as a means to advance cognitive load theory," Educational Psychologist, vol. 38, no. 1, pp. 63-71, 2003.

[151] H. F. Credidio, E. N. Teixeira, S. D. S. Reis, A. A. Moreira, and J. S. Andrade, "Statistical patterns of visual search for hidden objects," Scientific Reports, vol. 2, no. 1, p. 920, 2012.

[152] M. Burch, K. Kurzhals, and D. Weiskopf, "Visual task solution strategies. in public transport maps ET4S@GIScience," pp. 32-36, 2014.

[153] M. Burch, K. Kurzhals, M. Raschke, T. Blascheck, and D. Weiskopf, "A task-based view on the visual analysis of eye-tracking data," Eye Tracking and Visualization, Mathematics and Visualization, vol. 3, 2017.

[154] E. A. Maguire, D. G. Gadian, I. S. Johnsrude et al., "Navigation-related structural change in the hippocampi of taxi drivers," Proceedings of the National Academy of Sciences, vol. 97, no. 8, pp. 4398-4403, 2000. 
[155] J. Walker, Human Transit: How Clearer Thinking about Public Transit Can Enrich Our Communities and Our Lives, Island Press, Washington, DC, USA, 2012.

[156] M. Rosvall, A. Trusina, P. Minnhagen, and K. Sneppen, "Networks and cities: an information perspective," Physical Review Letters, vol. 94, 2005.

[157] S. Encarnação, M. Gaudiano, F. C. Santos, J. A. Tenedório, and J. M. Pacheco, "Fractal cartography of urban areas," Scientific Reports, vol. 2, no. 1, p. 527, 2012.

[158] M. J. Jacobson, "Problem solving, cognition, and complex systems: differences between experts and novices," Complexity, vol. 6, no. 3, pp. 41-49, 2001.

[159] O. Karaman, "Urban neoliberalism with islamic characteristics," Urban Studies, vol. 50, no. 16, pp. 3412-3427, 2013.

[160] A. Walker, "Introduction," The Asia Pacific Journal of Anthropology, vol. 2, no. 2, pp. 1-20, 2001.

[161] N. J. Habraken, "Cultivating complexity: the need for a shift in cognition," Complexity, Cognition, Urban Planning and Design, pp. 55-74, Springer, Berlin, Germany, 2016.

[162] J. Portugali, "What makes cities complex?," Complexity, Cognition, Urban Planning and Design, pp. 3-19, Springer, Berlin, Germany, 2016.

[163] L. Marcus, M. Giusti, and S. Barthel, "Cognitive affordances in sustainable urbanism: contributions of space syntax and spatial cognition," Journal of Urban Design, vol. 21, no. 4, pp. 439-452, 2016.

[164] K. Samuelsson, M. Giusti, G. D. Peterson, A. Legeby, S. A. Brandt, and S. Barthel, "Impact of environment on people's everyday experiences in Stockholm," Landscape and Urban Planning, vol. 171, pp. 7-17, 2018.

[165] W. S. Rauws, M. Cook, and T. Van Dijk, "How to make development plans suitable for volatile contexts," Planning Practice \& Research, vol. 29, no. 2, pp. 133-151, 2014.

[166] O. Yaski, J. Portugali, and D. Eilam, "City rats: insight from rat spatial behavior into human cognition in urban environments," Animal Cognition, vol. 14, no. 5, pp. 655-663, 2011.

[167] R. O. Kaaronen, "Affording sustainability: adopting a theory of affordances as a guiding heuristic for environmental policy," Frontiers in Psychology, vol. 8, p. 1974, 2017.

[168] C. Rawlinson and M. Guaralda, "Out of control," in Proceedings of the 8th International Design and Emotion Conference, pp. 1-12, University of the Arts London, Central Saint Martins College of Art \& Design, New Zealand, 2012.

[169] M. Hasanov and J. Beaumont, "The value of collective intentionality for understanding urban self-organization," Urban Research \& Practice, vol. 9, no. 3, pp. 231-249, 2016.

[170] S. Zhang, G. De Roo, and T. Van Dijk, "Urban land changes as the interaction between self-organization and institutions," Planning Practice \& Research, vol. 30, no. 2, pp. 160-178, 2015.

[171] "Landscape and urban planning," International Journal of Landscape Science, Planning and Design, vol. 139, p. 63, 2015.

[172] S. Nooteboom, "Impact assessment procedures for sustainable development: a complexity theory perspective," Environmental Impact Assessment Review, vol. 27, no. 7, pp. 645-665, 2007.

[173] B. Boonstra and L. Boelens, "Self-organization in urban development: towards a new perspective on spatial planning," Urban Research \& Practice, vol. 4, no. 2, pp. 99-122, 2011.

[174] S. Moroni and S. Cozzolino, "Action and the city. Emergence, complexity, planning," Cities, vol. 90, pp. 42-51, 2019.
[175] E. Lissandrello and J. Grin, "Reflexive planning as design and work: lessons from the port of amsterdam," Planning Theory \& Practice, vol. 12, no. 2, pp. 223-248, 2011.

[176] G. Ferilli, P. L. Sacco, and G. Tavano Blessi, "Beyond the rhetoric of participation: new challenges and prospects for inclusive urban regeneration," City, Culture and Society, vol. 7, no. 2, pp. 95-100, 2016.

[177] P. Marcuse, "From critical urban theory to the right to the city," City, vol. 13, no. 2-3, pp. 185-197, 2009.

[178] D. Sommer and P. L. Sacco, "Optimism of the will," Sustainability, vol. 11, no. 3, p. 688, 2019.

[179] R. Van Melik, I. Van Aalst, and J. Van Weesep, "Fear and fantasy in the public domain: the development of secured and themed urban space," Journal of Urban Design, vol. 12, no. 1, pp. 25-42, 2007.

[180] P. L. Sacco, S. Ghirardi, M. Tartari, and M. Trimarchi, "Two versions of heterotopia: the role of art practices in participative urban renewal processes," Cities, vol. 89, pp. 199-208, 2019.

[181] O. Devisch, A. Poplin, and S. Sofronie, "The gamification of civic participation: two experiments in improving the skills of citizens to reflect collectively on spatial issues," Journal of Urban Technology, vol. 23, no. 2, pp. 81-102, 2016.

[182] S.-K. Thiel and P. Fröhlich, "Gamification as motivation to engage in location-based public participation?" Progress in Location-Based Services 2016, pp. 399-421, Springer, Berlin, Germany, 2017.

[183] R. J. Lin, S. Ramakrishnan, H. Chang, S. Spraragen, and $\mathrm{X}$. Zhu, "Designing a web-based behavior motivation tool for healthcare compliance," Human Factors and Ergonomics in Manufacturing é Service Industries, vol. 23, no. 1, pp. 58-67, 2013.

[184] A. L. Hillman, "Expressive behavior in economics and politics," European Journal of Political Economy, vol. 26, no. 4, pp. 403-418, 2010.

[185] I. S. Mayer, "The gaming of policy and the politics of gaming: a review," Simulation \& Gaming, vol. 40, no. 6, pp. 825-862, 2009.

[186] K. Heljakka and P. Ihamäki, "Out of the classroom, into the park: gamified art experiences and learning through play in urban playscapes," in Proceedings of the 16th Annual Hawaii International Conference on Art \& Humanities, pp. 9-11, Honolulu, Hawaii, January 2018.

[187] J. Banfield and B. Wilkerson, "Increasing student intrinsic motivation and self-efficacy through gamification pedagogy," Contemporary Issues in Education Research, vol. 7, no. 4, pp. 291-298, 2014.

[188] H.-Y. Cheng, S.-W. Jian, D.-P. Liu, T.-C. Ng, W.-T. Huang, and H.-H. Lin, "Contact tracing assessment of COVID-19 transmission dynamics in Taiwan and risk at different exposure periods before and after symptom onset," JAMA Internal Medicine, vol. 180, no. 9, p. 1156, 2020.

[189] Y. J. Park, Y. J. Choe, O. Park et al., "Contact tracing during coronavirus disease outbreak, South Korea, 2020," Emerging Infectious Diseases, vol. 26, no. 10, pp. 2465-2468, 2020.

[190] S. Park, G. J. Choi, and H. Ko, "Information technologybased tracing strategy in response to COVID-19 in South Korea-privacy controversies," Jama, vol. 323, no. 21, p. 2129, 2020.

[191] R. Steinbrook, "Contact tracing, testing, and control of COVID-19-learning from taiwan," JAMA Internal Medicine, vol. 180 , no. 9, p. 1163, 2020.

[192] F. Rowe, O. Ngwenyama, and J.-L. Richet, "Contact-tracing apps and alienation in the age of COVID-19," European 
Journal of Information Systems, vol. 29, no. 5, pp. 545-562, 2020.

[193] S. Altmann, L. Milsom, H. Zillessen et al., "Acceptability of app-based contact tracing for COVID-19: cross-country survey study," JMIR mHealth and uHealth, vol. 8, no. 8, Article ID e19857, 2020.

[194] O. Plonsky and I. Erev, "To get people to adopt tracing applications, minimize the probability they will regret it," 2020.

[195] V. V. Makarov, A. E. Hramov, D. V. Kirsanov et al., "Interplay between geo-population factors and hierarchy of cities in multilayer urban networks," Scientific Reports, vol. 7, no. 1, 2017.

[196] U. Rossi, “The multiplex city," European Urban and Regional Studies, vol. 11, no. 2, pp. 156-169, 2004.

[197] S. Angel, A. M. Blei, D. L. Civco, and J. Parent, Atlas of Urban Expansion, Lincoln Institute of Land Policy Cambridge, Massachusetts, MA, USA, 2012.

[198] R. Florida, A. Rodriguez-Pose, and M. Storper, "Cities in a post-COVID world," in Papers in Evolutionary Economic Geography (PEEG) 2041, Utrecht University, Department of Human Geography and Spatial Planning, Utrecht, Netherlands, 2020.

[199] R. B. Patel and T. F. Burke, "Urbanization-an emerging humanitarian disaster," New England Journal of Medicine, vol. 361, no. 8, pp. 741-743, 2009.

[200] L. Potvin and C. M. Jones, "Twenty-five years after the ottawa charter: the critical role of health promotion for public health," Canadian Journal of Public Health, vol. 102, no. 4, pp. 244-248, 2011.

[201] M. Eriksson and B. Lindström, "A salutogenic interpretation of the Ottawa Charter," Health Promotion International, vol. 23, no. 2, pp. 190-199, 2008.

[202] M. Castleden, M. McKee, V. Murray, and G. Leonardi, "Resilience thinking in health protection," Journal of Public Health, vol. 33, no. 3, pp. 369-377, 2011.

[203] K. Y. Lai, C. Webster, S. Kumari, and C. Sarkar, "The nature of cities and the Covid-19 pandemic," Current Opinion in Environmental Sustainability, vol. 46, pp. 27-31, 2020.

[204] M. D. Lee, "Gamification and the psychology of game design in transforming mental health care," Journal of the American Psychiatric Nurses Association, vol. 22, no. 2, pp. 134-136, 2016.

[205] A. Tonkin and L. Whiting, Play and Playfulness for Public Health and Wellbeing, Taylor \& Francis Group, Milton Park, UK, The Science of Public Health, 1st edition, 2019.

[206] B. E. Kok, K. A. Coffey, M. A. Cohn et al., "How positive emotions build physical health," Psychological Science, vol. 24, no. 7, pp. 1123-1132, 2013.

[207] E. Grossi, G. Tavano Blessi, and P. L. Sacco, "Magic moments: determinants of stress relief and subjective wellbeing from visiting a cultural heritage site," Culture Medicine and Psychiatry, vol. 43, no. 1, pp. 4-24, 2019.

[208] L. D. Frank, M. A. Andresen, and T. L. Schmid, "Obesity relationships with community design, physical activity, and time spent in cars," American Journal of Preventive Medicine, vol. 27, no. 2, pp. 87-96, 2004.

[209] H. W. Kohl, C. L. Craig, E. V. Lambert et al., "The pandemic of physical inactivity: global action for public health," The Lancet, vol. 380, no. 9838, pp. 294-305, 2012.

[210] K. Gerst-Emerson and J. Jayawardhana, "Loneliness as a public health issue: the impact of loneliness on health care utilization among older adults," American Journal of Public Health, vol. 105, no. 5, pp. 1013-1019, 2015.
[211] P. L. Sacco, Economia Della Cultura, vol. 27, p. 165, 2017.

[212] D. Fancourt and S. Finn, 2019.

[213] C. D. Ryff and B. H. Singer, "Know thyself and become what you are: a eudaimonic approach to psychological well-being," Journal of Happiness Studies, vol. 9, no. 1, pp. 13-39, 2008.

[214] P. Miquelon and R. J. Vallerand, "Goal motives, well-being, and physical health: an integrative model," Canadian Psychology/Psychologie canadienne, vol. 49, no. 3, pp. 241-249, 2008.

[215] The concept of salutogenesis broadens the scope of public health policies from mainly addressing diseases and pathogenic factors to promoting healthy environments, individual and collective attitudes, and lifestyles, and more generally all kinds of factors that contribute to the maintenance of a healthy condition.

[216] The eudaimonic approach to well-being is based upon a balanced joint pursuit of physical, psychological, social and developmental dimensions of human existence. 